陈功, 李晓玲, 黄杰, 向玲, 孙雷, 杨进, 胥㫪, 黄应平.三峡水库剓归段消落带植物群落特征及其与环境因子的关系.生态学报, 2022,42(2) : 688-699.

Chen G, Li X L, Huang J, Xiang L, Sun L, Yang J, Xu T, Huang Y P.Characteristics of plant communities and their relationships with environmental factors in the water level fluctuation zone of the Zigui region of the Three Gorges Reservoir. Acta Ecologica Sinica, 2022,42(2):688-699.

\title{
三峡水库剓归段消落带植物群落特征及其与环境因子 的关系
}

\author{
陈 功 ${ }^{1}$, 李晓玲 ${ }^{1,2}{ }^{*}$, 黄 杰 $^{1}$, 向 玲 ${ }^{1}$, 孙 雷 $^{1}$, 杨 进 ${ }^{1,2}$, 胥 奉 ${ }^{1,2}$, 黄应平 ${ }^{1,2}$ \\ 1 三峡大学生物与制药学院, 宜昌 443002 \\ 2 三峡库区生态环境教育部工程研究中心 (三峡大学), 宜昌 443002
}

摘要: 消落带植被群落特征及物种多样性的研究一直是植物生态学和恢复生态学研究的热点。三峡水库的运行对消落带生态 系统造成了极大的影响,如引起绝大部分河岸带土著植物消失、生物多样性降低以及土壤侵蚀严重等一系列生态学问题。研究 消落带植物群落特征及其影响机制, 旨在丰富消落带新生湿地生态学研究内容, 为消落带植被的恢复、湿地保护和管理提供科 学依据。通过对三峡水库剓归段香溪河与童庄河陡坡消落带植物群落及其环境因子的实地调查, 并结合双向聚类分析及典范 对应分析 (CCA), 研究了三峡水库消落带植物群落特征、物种多样性及其与环境因子之间的关系。结果表明: (1) 在三峡水库 䄰归段消落带共发现维管植物 34 种,隶属于 15 科 32 属, 其中菊科 (Compositae) 和禾本科 (Gramineae) 种类数较多, 为优势物 种, 植物群落组成以草本植物为主,一年生和多年生草本植物为 23 种和 11 种, 分别占 $67.65 \%$ 和 $32.35 \%$,一年生植物占绝对优 势; (2) 随海拔升高, 物种数、Shannon 多样性指数、Pielou 均匀度从低海拔到高海拔随着海拔的增加而升高, 而 Simpson 优势度 指数指数从低海拔到高海拔呈下降趋势; (3) 双向聚类显示消落带主要包括 3 种植物群落: 狗牙根群落、狗尾草 + 马唐群落以及 鬼针草群落, 中低海拔以狗牙根单优群落为主, 高海拔为狗尾草、马唐、鬼针草及苍耳等为主的共优群落。CCA 结果表明海拔 与水淹时间是影响消落带植被群落物种组成的主要因子, TN 与 TK 是影响群落物种分布格局的次要因子, 同时消落带土壤贫 㾑, 受 $N 、 K$ 的限制。库区植物群落物种多样性仍在下降, 需对植物群落和环境因子进行长期的监测与研究。

关键词:三峡水库;消落带;物种多样性; 环境因子

\section{Characteristics of plant communities and their relationships with environmental factors in the water level fluctuation zone of the Zigui region of the Three Gorges Reservoir}

CHEN Gong ${ }^{1}$, LI Xiaoling ${ }^{1,2, *}$, HUANG Jie ${ }^{1}$, XIANG Ling $^{1}$, SUN Lei ${ }^{1}$, YANG Jin $^{1,2}$, XU Tao ${ }^{1,2}$, HUANG Yingping ${ }^{1,2}$

1 College of Biological and Pharmaceutical Science, Three Gorges University, Yichang 443002, China

2 Collaborative Innovation Center for Geo-hazards and Eco-Environment in Three Gorges Area, Yichang 443002, China

\begin{abstract}
River systems around the globe are increasingly affected by damming to satisfy increasing demands for hydroelectricity, flood mitigation and reliable water supplies. The impoundment of the reservoirs can significantly alter river flow, shorelines, sediment and aquatic fauna and flora and can result in the loss of original riparian vegetation. After the first impoundment of the Three Gorges Reservoir (TGR) in June 2003 and the complete impoundment in 2010, the water
\end{abstract}

基金项目: 国家自然科学基金项目 (51779127,51209122); 三峡库区生态环境教育部工程研究中心开放基金( KF2018-02)

收稿日期:2020-08-27; 采用日期:2021-09-28

*通讯作者 Corresponding author.E-mail: lixiaolinggz@126.com 
level of the reservoir fluctuates from $145 \mathrm{~m}$ a.s.l in summer (May to September) to $175 \mathrm{~m}$ in winter (October to April), resulting in formation of the water level fluctuation zone (WLFZ) with a total area of $350 \mathrm{~km}^{2}$ in the Reservoir. Compared with other reservoirs, the hydrological regime of the TGR is the exactly opposite of the natural flood rhythms of the Yangtze River with prolonged inundation duration (nearly half a year) and deep submergence depth ( up to $30 \mathrm{~m}$ ). The operation of the Three Gorges Reservoir had significant effects on the ecosystem of the riparian zone, causing a series of ecological problems such as the disappearance of original vegetation and reduced biodiversity in most of the riparian zone, as well as severe soil erosion. These changes might alter plant community characteristics in the WLFZ of the TGR. The study of plant community structure and species diversity in the WLFZ has been a research hotpot in plant ecology and restoration ecology. The purpose of studying the characteristics of plant communities and their influencing mechanisms in the WLFZ is to enrich the ecological research content of newborn wetlands, and to provide a scientific basis for the vegetation restoration, wetland protection and management in the WLFZ. The height, coverage and frequency of each plant species and the soil properties were measured at each elevation zone $(145-155 \mathrm{~m}, 155-165 \mathrm{~m}$, and 165-175 m) in the WFLZ of the Zigui region of the Three Gorges Reservoir (ZRTGR) in 2018. The two-way clustering analysis and canonical correspondence analysis ( CCA) were used to analyze the spatial variations of the plant community characteristics and determine the key environmental factors influencing vegetation. The main results were as follows: (1) a total of 34 species of vascular plants, belonging to 15 families and 32 genera, were recorded in the WLFZ of the ZRTGR, with abundant species of Compositae and Gramineae. Vegetation was dominated by herbaceous plants amog which the annual herbs (i.e. Setaria viridis, Digitaria sanguinalis, Echinochloa crusgalli, Bidens pilosa, and Xanthium strumarium) and perennial herbs (i.e. Cynodon dactylon and Cyperus rotundus) accounted for 67.65\% (23) and 32.35\% (11) of the total number of species, respectively. (2) Species diversity showed an increasing trend with elevation and had significant differences between low, middle and high elevation area $(P<0.05)$. The species number, Shannon-Wiener diversity index, and Pielou evenness index of the plant community increased with the increasing elevation from the low to high elevation area, whilamonge the Simpson dominance index decreased with the increasing elevation. (3) Using two-way clustering analysis methods, the vegetation in the WLFZ consisted of three main plant community types: Ass. C. dactylon, Ass. S. viridis $+D$. sanguinalis and Ass. B. pilosa. The low and middle altitudes are dominated by monodominant community of $C$. dactylon, while the high altitudes are dominated by co-optimal communities of Setaria viridis, D. sanguinalis, B. pilosa and X. sibiricum. The CCA showed that elevation and flooding duration were the most important factors influencing the species composition of the plant community in the WLFZ, while TN and TK were the secondary important factors influencing the species distribution pattern of the community. The soil in the WLFZ was poor and limited by $\mathrm{N}$ and $\mathrm{K}$ nutrients. The diversity of plant communities in the reservoir area is still declining, which requires long-term monitoring and research of plant communities and environmental factors.

Key Words: Three Gorges Reservoir; riparian zone; species diversity; environmental factors

近年来, 水库消落带植物群落的演替、群落分布特征以及消落带植被的恢复重建是消落带生态系统研究 的重点和热点 ${ }^{[1-2]}$ 。水库消落带又称涨落带或涨落区, 是指水库季节性水位涨落而使周边被淹没土地周期 性地出露于水面的一段特殊区域, 是水生生态系统和陆生生态系统交替控制的过渡地带 ${ }^{[3]}$ 。消落带植被是 长期生活在陆地的植物与周期性水陆交替变化生境下协同进化产生的, 具有特定的生态适应性, 其作为水库 管理的重要对象, 是生态系统功能的主体一一消落带生态系统的重要组成部分,在保护水域生态安全、保护水 质、稳定堤岸、保持生境连通性和维持生物多样性等生态功能方面发挥重要作用 ${ }^{[4-5]}$ 。消落带的季节性水位 导致区域内光照、压力、氧含量等环境因素改变, 对植物的光合作用、呼吸作用、生长繁育、繁殖及物候产生巨

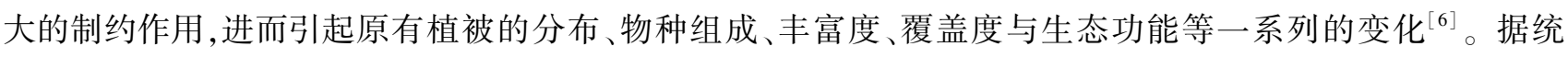
计, 到 1997 年,世界 $20 \%$ 以上的消落带植物群落已不复存在, 剩余部分也在极迅速地消失中 ${ }^{[7]}$ 。 Nilsson 
等 ${ }^{[8-11]}$ 研究发现, 水库建成 60-70a 后消落带植被物种多样性才能恢复到稳定状态。生物多样性和生态系 统功能之间具有正向关系, 表明了保护生物多样性以维持生态系统功能及其相关服务的重要性 ${ }^{[12-13]}$ 。可见 开展有关消落区物种多样性空间分布格局的研究对于评估建坝对于植被群落结构的影响及植被恢复具有重 要意义。

作为世界上最大的水库,三峡水库从 2003 年起开始蓄水,三峡工程蓄水位采用 $175 \mathrm{~m}$ 的水库规模和“蓄 清排浑” 的水位调度方式 ${ }^{[14]}$ 。受反季节性水库水位周期性涨落的影响, 三峡水库消落带对外界扰动非常敏 感, 导致了消落带水土流失、生境退化及生物多样性减少等生态系统退化状况 ${ }^{[15-16]}$ 。刘维暐等对三峡水库干 流和库湾消落带的植物群落物种分布进行了本底调查, 结果显示 2011 年水库消落带植物群落格局 (61 科 169 属 231 种) 较 2002 年三峡工程建成前的自然消落带维管植物 (83 科 240 属 405 种) 发生了显著变化, 消落带 植被以草本植物居多, 其中一年生草本植物 105 种,多年生草本植物 75 种,物种减少了 $42.96 \%$, 有 3/4 的灌 木物种消失 ${ }^{[5,17]}$ 。这种水淹时间更长, 水淹深度更大的反季节水位节律造成了木本物种和竞争性多年生草本 植物的损失。而竞争性的一年生草本植物和耐涝的河岸草本植物作为最丰富的物种, 即使在这种长期缺氧的 条件下也仍然能够生长 ${ }^{[18]}$ 。

其次, 三峡水库水位节律的变化、水淹深度的增加、河水的冲刷及其可能对气候造成的一系列影响,都对 三峡库区土壤性质的稳定与动态产生显著影响 ${ }^{[19]}$ 。研究发现水库长期水淹及干湿交替势必会引起土壤理化 性状变化 ${ }^{[20]}$, 而土壤元素含量是引起其他特性变化的主要原因 ${ }^{[21]}$ 。在三峡水库蓄水 $4 \mathrm{a}$ 后消落带土壤由微 碱性 $(\mathrm{pH}$ 值 $=7.91)$ 变为碱性 $(\mathrm{pH}$ 值 $=8.14)$, 有机质、全氮及速效钾含量低于未水淹土壤, 水淹造成消落带 土壤养分流失 ${ }^{[21]}$ 。Ye 等通过对整个三峡库区消落带植物-土壤的互作关系的研究也发现, 由于三峡库区洪 水节律的改变, 也使消落带土壤 $\mathrm{N}$ 和 $\mathrm{P}$ 较非洪水淹没区分别下降 $17 \%$ 和 $24 \%$, 使植物丰富度和多样性 下降 ${ }^{[20]}$ 。

这些研究提供了许多关于消落带植物群落动态变化的信息, 对于深人揭示消落带动态变化规律具有一定 的理论参考价值。而目前有关消落带植被研究仍处于初期阶段, 随着水淹年限的延长, 消落带由于受到冬季 蓄水淹没和夏季洪水冲刷, 受到消落带生境的复杂性及外界干扰的影响, 土壤理化性质及水文特征等生境要 素在空间和时间分布上具有较高的异质性 ${ }^{[16]}$, 库区植物群落结构仍具有很强的不稳定性和多变性, 特别是 三峡水库生态系统较为脆弱的典型陡坡消落带植物群落特征及其与土壤环境因子的关系的研究报道较少, 其 物种空间分布特征和多样性仍需进一步监测和研究。因此, 本文以三峡水库剓归库区香溪河和童庄河消落带 为研究对象, 该研究区域沿河两岸坡度普遍大于 $20^{\circ}$, 平均为 $39^{\circ}$, 为典型的陡坡消落带 ${ }^{[22]}$, 拟着重研究三峡 库区消落带在经历 $15 \mathrm{a}$ 水位涨落 (长期生境干湿交替) 后植物群落的结构变化特征及其与环境因子的关系, 同时对消落带植被现状进行分析, 探讨消落带植物群落特征的累积效应及其影响机制, 旨在丰富消落带新生 湿地生态学研究内容, 为消落带植被的恢复、湿地保护和管理提供科学依据。

\section{1 研究区域与研究方法}

\section{1 研究区域概况}

调查研究区域选取三峡水库剓归段长江一级支流香溪河 $\left(110^{\circ} 25^{\prime} \mathrm{E}-111^{\circ} 06^{\prime} \mathrm{E}, 30^{\circ} 57^{\prime} \mathrm{N}-31^{\circ} 34^{\prime} \mathrm{N}\right)$ 与童 庄河 $\left(110^{\circ} 41^{\prime} \mathrm{E}-110^{\circ} 75^{\prime} \mathrm{E}, 30^{\circ} 54^{\prime} \mathrm{N}-30^{\circ} 91^{\prime} \mathrm{N}\right)$ 为研究对象。香溪河河口距三峡大坝 $34.5 \mathrm{~km}$, 为三峡水库库 首第一支流, 香溪河干流全长 $94.0 \mathrm{~km}$, 流域面积 $3183.0 \mathrm{~km}^{2}$, 干流受三峡水库 $175.0 \mathrm{~m}$ 蓄水影响河段 $35.9 \mathrm{~km}$, 消落带平均宽度 $0.21 \mathrm{~km}$, 消落带面积 $7.4 \mathrm{~km}^{2}$, 占三峡库区消落带总面积的 $2.1 \%$ 。童庄河也为三峡水库长江 一级支流, 河口距三峡大坝 $42.0 \mathrm{~km}$, 全长 $36.6 \mathrm{~km}$, 流域面积 $248.0 \mathrm{~km}^{2}$, 多年平均流量 $6.4 \mathrm{~m}^{3} / \mathrm{s}^{[21]}$ 。香溪河 和童庄河分别位于长江的左岸和右岸相对位置, 研究区域沿河两岸多为陡坡峡谷, 消落带坡度大于 $20^{\circ}$ 的区 域占 $73 \%$, 平均为 $39^{\circ}$, 为典型的陡坡消落带 ${ }^{[22]}$ 。

研究区域属于亚热带大陆性季风气候, 降水量较多,多年降雨平均值在 900-1 $200 \mathrm{~mm}$ 之间, 相对湿度偏 
高, 多年平均气温为 $17.24{ }^{\circ} \mathrm{C}$, 高温期平均气温在 $25.0{ }^{\circ} \mathrm{C}$ 左右, 土壤主要类型为黄棕壤和石灰土 ${ }^{[5,21,23]}$ 。

\section{2 野外调查}

根据三峡水库的水位变化范围,本研究于 2018 年 7-8 月对三峡库区秭归段 (香溪河,童庄河流域) 消落 带取谭家湾 $(A)$ 、万古寺 $(B)$ 、八字门 $(C)$ 、海事处 $(D)$ 、龙潭河大桥 $(E) 、$ 杨家龙小学 $(F) 6$ 个样点, 每个样点 划分 145-155 m;155-165 m;165-175 $\mathrm{m}$ 三个水位梯度,每个水位梯度带随机设置 6 个 $1 \mathrm{~m} \times 1 \mathrm{~m}$ 的样方进行 调查, 其中海事处 $(\mathrm{D})$ 、龙潭河大桥 $(\mathrm{E})$ 与杨家龙小学 $(\mathrm{F})$ 样点由于消落带上部为农田与柑橘林, 人为干扰严 重, 故在 165-175 m 梯度仅取 3 个有效样方调查, 杨家龙小学( F) 155-165 m 水位梯度仅取五个有效样方, 共调查 98 个样方。调查方法具体如下:

\subsection{1 经纬度及样点特征记录}

在采样点实地使用 GPS 定位记录其经纬度, 并与根据谷歌地图 (http://www.google.cn/maps) 查询经纬度 进行比对更正,使用坡度仪测量样点坡度,罗盘测定坡向,样点信息如表 1 。

\section{表 1 取样点基础信息}

Table 1 Basic information of sampling sites

\begin{tabular}{|c|c|c|c|c|c|c|}
\hline $\begin{array}{c}\text { 样点编号 } \\
\text { Sample code }\end{array}$ & $\begin{array}{l}\text { 样点 } \\
\text { Sampling sites }\end{array}$ & $\begin{array}{l}\text { 海拔/m } \\
\text { Elevation }\end{array}$ & $\begin{array}{l}\text { 经度 } /\left({ }^{\circ}\right) \\
\text { Longitude }\end{array}$ & $\begin{array}{c}\text { 纬度 } /\left({ }^{\circ}\right) \\
\text { Latitude }\end{array}$ & $\begin{array}{c}\text { 坡度 } /\left({ }^{\circ}\right) \\
\text { Slope }\end{array}$ & $\begin{array}{l}\text { 坡向 } \\
\text { Aspect }\end{array}$ \\
\hline A & 宜昌市剓归县倒树湾 & $145-175$ & 110.7835 & 30.1001 & 16 & Eastward \\
\hline B & 宜昌市剓归县万古寺 & $145-175$ & 110.7678 & 31.0240 & 34 & Northwest \\
\hline $\mathrm{C}$ & 宜昌市䄰归县八字门 & $145-175$ & 110.7673 & 30.9732 & 24 & Northeast \\
\hline $\mathrm{D}$ & 宜昌市剓归县海事处 & $145-175$ & 110.7520 & 30.9545 & 27 & Southeast \\
\hline $\mathrm{E}$ & 宜昌市剓归县龙潭河大桥 & $145-175$ & 110.7495 & 30.9226 & 18 & Northeast \\
\hline $\mathrm{F}$ & 宜昌市剓归县杨家龙小学 & $145-175$ & 110.7418 & 30.9254 & 20 & Westward \\
\hline
\end{tabular}

\subsection{2 植物群落结构调查}

记录调查区域样方内物种名、株数、盖度、高度、密度。植物种名鉴定依据中国植物图像库 (http://ppbc. iplant.cn/) 和《中国植物志》。

\subsection{3 土壤因子调查}

用环刀在调查过植被的样方表层 $(0-20 \mathrm{~cm})$ 取土壤,采用梅花形布点混合取样法,并装袋编号, 带回实 验室分析。土壤环境因子测定指标有: $\mathrm{pH}$ 值、有机质含量 $(\mathrm{OM})$ 、总氮 $(\mathrm{TN})$ 、总磷 $(\mathrm{TP})$ 、总钾 $(\mathrm{TK})$ 、速效磷 $(\mathrm{AP})$ 、速效钾 $(\mathrm{AK})$ 、铵态氮 $\left(\mathrm{NH}_{4}^{+}-\mathrm{N}\right)$ 、硝态氮 $\left(\mathrm{NO}_{3}^{-}-\mathrm{N}\right)$ 及土壤含水量 $(\mathrm{SM})$ 等, 土壤 $\mathrm{pH}$ 值用电位法测定 ${ }^{[24]}$, $\mathrm{OM}$ 测定采用 $\mathrm{K}_{2} \mathrm{Cr}_{2} \mathrm{O}_{7}$ 容量法, TN 测定采用凯氏定氮法 ${ }^{[25]}$, TP、AP 测定采用 $\mathrm{HClO}_{4}-\mathrm{H}_{2} \mathrm{SO}_{4}$ 消煮-钿锑抗比色 法 ${ }^{[26]}, \mathrm{TK}$ 测定采用 $\mathrm{HF}-\mathrm{HClO}_{4}$ 消煮- 火焰光度法, $\mathrm{AK}$ 测定采用乙酸铵提取 - 火焰光度法 ${ }^{[27]}, \mathrm{NH}_{4}-\mathrm{N}$ 测定采用 $2 \mathrm{~mol} / \mathrm{L} \mathrm{KCl}$ 浸提-靛酚蓝比色法 ${ }^{[28]}, \mathrm{NO}_{3}-\mathrm{N}$ 测定采用酚二磺酸比色法 ${ }^{[29]}, \mathrm{SM}$ 测定采用土壤水分测定仪 法 ${ }^{[30]}$,各海拔土壤生境因子见表 2 。

\section{2 .4 水文因素}

根据中华人民共和国长江海事 (https://cj.msa.gov.cn/) 的逐日库区水位数据, 统计各样点水位计算平均 值,具体水位变化如图 1。

1.3.1 重要值和 $\alpha$ 多样性指数的计算

选取重要值作为评价群落中物种相对重要性的综合数量指标 ${ }^{[18]}$ 。

重要值 $=($ 相对高度 + 相对盖度 + 相对密度 $) / 3$

$\alpha$ 多样性指数采用 Shannon 多样性指数、Pielou 均匀度指数和 Simpson 优势度指数作为评价指标:

Shannon 多样性指数:

$$
\begin{gathered}
H=-\sum P_{i} \ln P_{i} \\
E=H / \ln S
\end{gathered}
$$

Pielou 均匀度指数: 
表 2 土壤环境因子分析

Table 2 Statistic analysis of soil environmental factors

\begin{tabular}{lccccc}
\hline $\begin{array}{l}\text { 因子 } \\
\text { Factor }\end{array}$ & $\begin{array}{c}\text { 平均数 } \\
\text { Mean }\end{array}$ & $\begin{array}{c}\text { 最小值 } \\
\text { Minimum }\end{array}$ & $\begin{array}{c}\text { 最大值 } \\
\text { Maximum }\end{array}$ & $\begin{array}{c}\text { 标准偏差 } \\
\text { SD }\end{array}$ & $\begin{array}{c}\text { 变异系数 } \\
\mathrm{CV}\end{array}$ \\
\hline $\mathrm{pH}$ & 7.99 & 7.71 & 8.21 & 0.15 & $1.92 \%$ \\
$\mathrm{OM} /(\mathrm{g} / \mathrm{kg})$ & 24.28 & 21.22 & 27.23 & 1.99 & $8.21 \%$ \\
$\mathrm{SM} / \%$ & 31.77 & 3.30 & 50.70 & 11.30 & $35.56 \%$ \\
$\mathrm{TP} /(\mathrm{g} / \mathrm{kg})$ & 0.94 & 0.71 & 1.21 & 0.18 & $19.04 \%$ \\
$\mathrm{TN} /(\mathrm{g} / \mathrm{kg})$ & 0.88 & 0.64 & 1.12 & 0.12 & $13.91 \%$ \\
$\mathrm{TK} /(\mathrm{g} / \mathrm{kg})$ & 20.36 & 20.05 & 20.87 & 0.25 & $1.23 \%$ \\
$\mathrm{AP} /(\mathrm{mg} / \mathrm{kg})$ & 15.16 & 8.98 & 17.89 & 2.79 & $18.43 \%$ \\
$\mathrm{AK} /(\mathrm{mg} / \mathrm{kg})$ & 93.00 & 85.01 & 97.65 & 4.21 & $4.53 \%$ \\
$\mathrm{NH}_{4}^{+}-\mathrm{N} /(\mathrm{mg} / \mathrm{kg})$ & 6.49 & 5.55 & 6.98 & 0.44 & $6.76 \%$ \\
$\mathrm{NO}_{3}^{-}-\mathrm{N} /(\mathrm{mg} / \mathrm{kg})$ & 10.55 & 6.65 & 12.88 & 2.07 & $19.60 \%$ \\
\hline
\end{tabular}

$\mathrm{OM}$ : 有机质 Organic matter; SM : 土壤含水量 Soil Moisture;TP : 总磷 Total phosphorus;TN : 总氮 Total nitrogen; TK : 总钾 Total potassium; AP : 速效 磷 Available phosphorus; $\mathrm{AK}$ : 速效钾 Available potassium; $\mathrm{NH}_{4}^{+}-\mathrm{N}$ : 氨态氮 Ammonia nitrogen; $\mathrm{NO}_{3}^{-}-\mathrm{N}$ : 硝态氮 Nitrate

Simpson 优势度指数: $\quad D=\sum^{2} P_{i}$ 式中, $P$ 为第 $i$ 种的重要值; $S$ 为样方内出现的物种数, $N$ 为样方内出现的总物种数。

实验数据采用 SPSS 20.0 统计分析软件中 one-way ANOVA 对不同水位梯度带数据进行差异显著性检验。 若差异显著,采用 LSD 进行多重比较,显著性水平取 $P$ $<0.05$ 。选用 Excel 数据分析运算和 Origin 8 制图。

\subsection{2 双向聚类分析}

植被数量分类是用数学方法来完成分类过程, 旨在 揭示生态关系, 即分类的结果能够反映一定的生态规 律 ${ }^{[31]}$ 。双向聚类可以同时对样本和变量进行聚类, 将 原始数据矩阵聚成一系列子矩阵,一个子矩阵表示一

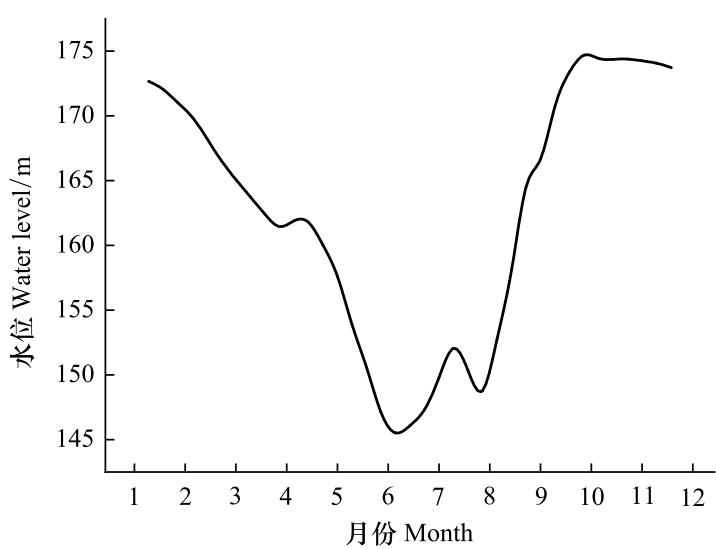

图 1 三峡水库水位变化

Fig.1 The water level changes in the Three Gorges reservoir 类,其基本思想是研究样本和变量间的局部对应关系, 通过确定其具体的结构来提高聚类效果并且増强聚类结果的可解释性 ${ }^{[32]}$ 。双向聚类分析可以很直观的了解 群落中各物种的分布状况、分类以及各群落之间的相似程度。本研究选取重要值大于 $5 \%$ 的优势物种进行聚 类分析,采用 PC-ORD 5.0 生态学软件包中的双向聚类分析方法对群落及群落中的物种进行数量分类。

\subsection{3 典范对应分析}

本研究采用 CANOCO 5.0 软件典范对应分析 (Canonical Correspondence Analysis, CCA) 对三峡水库䄰归 段消落区植物群落样方、物种和环境因子之间的相关关系进行分析。

对三峡水库剓归段消落区的植被群落和 12 个环境因子的 CCA 分析,群落矩阵和环境因子矩阵经过 $\lg (x+1)$ 转换使数据更趋于正态分布, 同时为了证明 CCA 分析中环境因子对群落解释量的显著性, 对试验进 行了 Monte Carlo 显著性检验。

\section{2 结果与分析}

2.1 三峡库区剓归段消落带不同海拔的土壤环境因子异质性

本研究调查的三峡库区剓归段消落带中,各生境因子最大值和最小值相差较大,甚至达几十倍。变异系 数衡量土壤样品数据的变异程度,其大小能判定土壤环境因子的变异状态。由表 2 可以看出三峡库区䄰归段 
消落带不同海拔区域的土壤环境因子中 $\mathrm{SM}$ 变异系数最大, 其次是 $\mathrm{NO}_{3}^{-}-\mathrm{N} 、 \mathrm{TP} 、 \mathrm{AP} 、 \mathrm{TN} 、 \mathrm{OM}$, 变异程度较弱的 是 $\mathrm{NH}_{4}^{+}-\mathrm{N} 、 \mathrm{pH} 、 \mathrm{TK} 、 \mathrm{AK}$ 。这表明研究区域内土壤理化性质差异较大, 消落带生境条件复杂表现出异质性。

2.2 植物群落的物种组成

本次调查在三峡水库剓归段消落带共发现维管植物 34 种, 隶属于 15 科 32 属, 其中菊科 (Compositae) 8 属 9 种, 禾本科 (Gramineae ) 7 属 7 种, 豆科 (Leguminosae) 与大戟科 (Euphorbiaceae) 3 属 3 种, 苋科 (Amaranthaceae) 2 属 2 种, 葫芦科 (Cucurbitaceae)、锦葵科 (Malvaceae)、苶科 (Polygonaceae)、马齿苋科 (Portulacaceae)、茄科 (Solanaceae)、伞形科 (Umbelliferae) )、桑科 (Moraceae)、莎草科 (Cyperaceae)、玄参科 (Scrophulariaceae) 均为 1 属 1 种。菊科种类最为丰富,其次是禾本科, 分别占物种总数的 $26.47 \%$ 和 $20.59 \%$, 在三峡库区消落带剓归段植被分布中占据重要地位。接着为豆科、大戟科、苋科,分别占物种总数的 $8.82 \%$ 、 $8.82 \% 、 5.88 \%$ 。调查区域内单属单种的植物占有相当大的比例, 共有 8 科 (即 8 属 8 种), 占总科数的 $53.33 \%$, 占总属数的 $25 \%$, 占总种数的 $23.53 \%$ 。库区所调查物种中包含一年生草本 23 种 (67.65\%), 多年生草本 11 种 $(32.35 \%)$ 。在不同海拔区域, 145- $155 \mathrm{~m}$ 海拔梯度共发现维管植物 10 科 18 属 20 种, 其中一年生植物 17 种 ( $85 \%$ ), 多年生植物 3 种 (15\%), 禾本科占 30\% (6 种), 菊科占 $20 \%$ (4 种); $155-165 \mathrm{~m}$ 海拔梯度共发现维 管植物 9 科 18 属 19 种, 其中一年生植物 17 种 ( $89.47 \%$ ), 多年生植物 2 种 ( $10.53 \%$ ), 禾本科占 $31.58 \%$ (6 种), 菊科占 $26.32 \%$ (4 种) ; $165-175 \mathrm{~m}$ 海拔梯度共发现维管植物 12 科 26 属 28 种, 其中一年生植物 18 种 $(64.29 \%)$, 多年生植物 10 种 $(35.71 \%$ ), 菊科和禾本科各占 $28.57 \%$ (均 8 种) (图 2)。可见,随海拔升高, 高海 拔区域物种数最多,一年生和多年生草本植物增加,菊科和禾本科植物为优势物种。

\section{3 群落多样性指数}

从图 3 可知,在不同的调查样点和海拔梯度下,物种数、Shannon 多样性指数及 Pielou 均匀度指数均差异 显著 $(P<0.05)$ 。物种数、Shannon 多样性指数、Pielou 均匀度指数从低海拔到高海拔随着海拔的增加而升高, 而Simpson 优势度指数指数从低海拔到高海拔呈下降趋势。物种数、Shannon 多样性指数及 Simpson 优势度 指数在低海拔区域 $(145-155 \mathrm{~m})$ 与中海拔区域 $(155-165 \mathrm{~m})$ 间差异不显著 $(P>0.05)$, 而与高海拔区域 (165-175m) 间差异显著 $(P<0.05)$ 。Pielou 均匀度指数在三个海拔梯度间均呈差异显著 $(P<0.05)$ 。

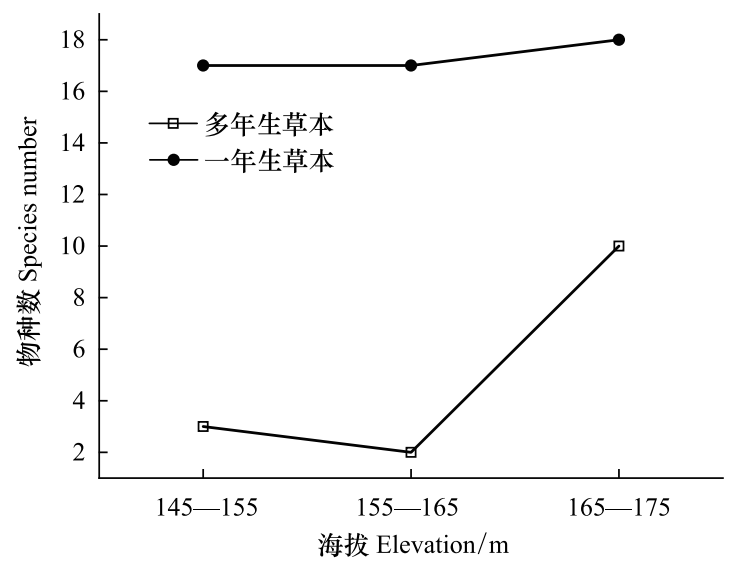

图 2 库区不同海拔生活型分布

Fig.2 Distribution of life forms by altitude in the Three Gorges reservoir

\section{4 植物群落的双向聚类分析}

对 98 个样方群落中的 34 个物种进行数量分类, 以 $37.5 \%$ 为阙值, 可以归为 3 种植物群落类型 (图 4), 依 据植物群落每一层中平均重要值较大的优势物种对群落进行命名,3 种植物群落类型的表述如下：

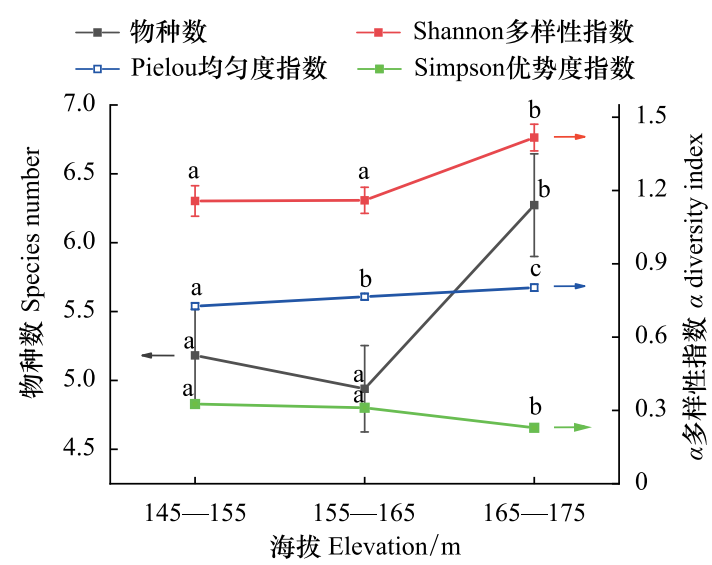

图 3 库区群落多样性指数

Fig.3 $\alpha$-Diversity Index in the Three Gorges reservoir 


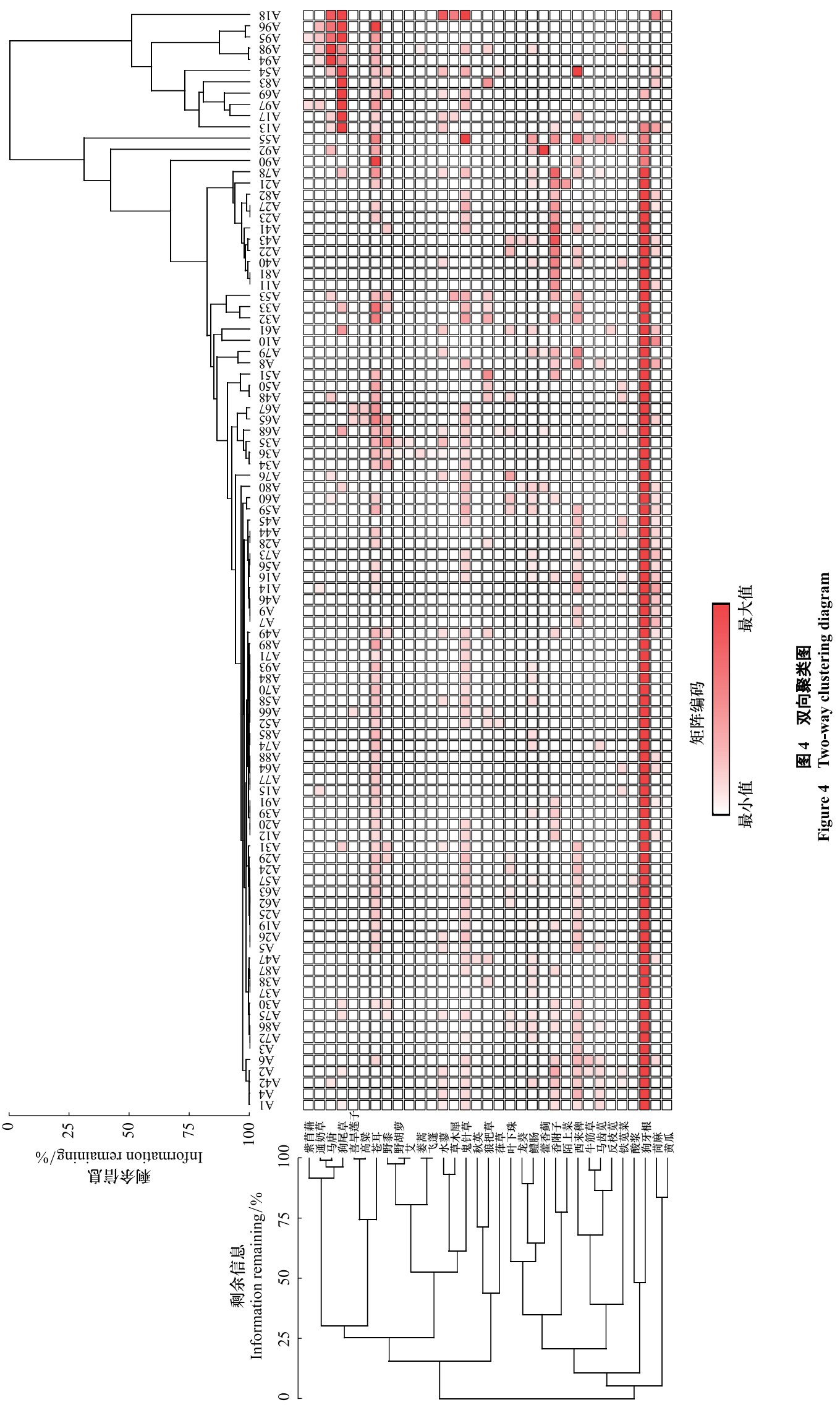


(1) 狗牙根 (Cynodon dactylon) 群落

草本植物群落, 主要包括狗牙根、香附子(Cyperus rotundus)、西来稗 (Echinochloa crusgalli)、鬼针草( Bidens pilosa)、狗尾草 (Setaria viridis)、苍耳 (Xanthium strumarium)。伴生种有苟麻 (Abutilon theophrasti)、醴肠 (Eclipta prostrata)、马唐(Digitaria sanguinalis)、野乘(Eriochloa villosa) 等。这一类群主要分布在 $145-165 \mathrm{~m}$ 水位梯度, 即消落带中下部, 包括 86 个样方共 32 个物种。

(2) 狗尾草+马唐群落

草本植物群落, 主要包括狗尾草、马唐、鬼针草、苍耳、狗牙根。伴生种有水蓼 (Polygonum hydropiper)、通 奶草 (Euphorbia hypericifoli)、草木犀(Melilotus officinalis) 等。这一类群主要分布在 165-175 m 水位梯度, 包 括 11 个样方共 19 个物种。

(3) 鬼针草群落

草本植物群落, 主要包括鬼针草、苍耳、西来稗、狗牙根、苟麻、香附子。伴生种有水蓼、狗尾草、醴肠、野㯟 等。这一群落主要分布在 $165-175 \mathrm{~m}$ 水位梯度,包括 1 个样方共 10 个物种。

2.5 三峡水库䄰归段消落区群落空间分布与环境因子的相关性分析

三峡水库剓归段消落区群落空间分布与环境因子的 CCA 排序如图 5。前 4 典范轴累计解释了群落变化 的 $55.04 \%$,轴 1 与轴 2 的物种一环境相关系数分别为 0.9417 和 0.9138 , 另外前两轴的特征值的和占总特征值 的 $49.75 \%$, 包含了大部分排序信息, 故采用前两轴的数据来分析植物群落、样点与环境因子的关系。

海拔与水淹时间与轴 1 的相关性最高, 分别为 0.7710 与 -0.7374 。但这 2 个因子之间包含一定的相关性 而且都和水淹干扰有一定关联, 如随着海拔的升高, 区域的水淹时间也会相应减少 (图 $5 \mathrm{~A}$ )。因此, 与水淹干 扰有关的干扰因子在决定消落带植物群落结构的这些生境因素中起着主导作用。土壤环境因子与第二排序 轴均呈正相关, 其中 TN 与 TK 与轴 2 的相关性相对较高, 分别为 0.3097 和 0.2627 。各植物群落在排序空间中 的位置可以反映群落的生态学特征。

从图 5B 可看出,沿着第 1 排序轴由左至右海拔高度升高, 水淹时间减少,样点分布顺序依次为: 低海拔 区域 (145-155 m), 包括 A1-F1; 中海拔区域 (155-165 m) ,包括 A2-F2; 高海拔区域,包括 A3-F3。如图 5A 沿第一排序轴,各物种对环境表现出明显的选择性, 轴 1 反映了三峡库区生境的海拔梯度, 酸浆(Physalis alkekengi)、牛筋草 (Eleusine indica)、陌上菜 (Lindernia procumbens) 等分布于第一轴的左侧,代表了 145-155 $\mathrm{m}$ 低海拔区域; 西来稗、狗牙根、鬼针草、香附子等则主要分布在中海拔区域; 通奶草、马唐、飞蓬 (Erigeron acer ) 等分布于第一轴右侧, 分别代表了 165-175 m 高海拔区域。沿第 2 轴从下到上, TN 、TK 上升, 植物群落 在第 2 排序轴上的变化没有第 1 排序轴明显, 说明海拔和水淹影响对消落带植物群落分布格局的形成所起的 作用要强于 TN 和 TK 的作用, 尽管三峡水库消落带植物群落的空间分布是多种因子综合作用的结果, 但海拔 和水淹影响在植物群落空间格局的形成中起着主导作用。

\section{3 讨论}

水库消落带植物群落在物种组成、群落结构及空间分布等方面明显不同于相邻的陆地或者水生植物群 落 ${ }^{[27-28]}$ 。Ye 等和 $\mathrm{Lu}$ 等在调查三峡水库蓄水对消落带植物群落的影响发现, 以草本植物群落为主, 特别是一 年生植物占据主要优势, 木本植物群落较少, 表明消落带受到持续不断水淹-干旱和土壤环境因子干扰, 这些 干扰造成消落带群落结构趋于简单化 ${ }^{[33-34]}$ 。2018 年的调查结果包括维管植物 15 科 32 属 34 种, 与 2010 年 ( 29 科 59 属 64 种) 和 2014 年 (23 科 49 属 50 种 ${ }^{[26-27]}$ 相比较, 植物科、属、种数持续下降; 与三峡水库蓄水前 调查的香溪河流域河岸带植物群落的物种数 (127 科,404 属, 633 种 $)^{[35]}$ 相比, 其物种数亦急剧降低。消落带 生活型组成亦有差异, 2014 年调查结果表明一年生植物占比 $54.0 \%, 4 \mathrm{a}$ 后消落带一年生植物明显上升, 达到 $67.6 \%$ 。本文结果与 Nilsson 等的研究结果一致 ${ }^{[8-11]}$ 。可见, 随着水库蓄水周期的延长消落带植物群落的科、 属、种均逐渐下降,一年生植物所占比例逐渐增加。 

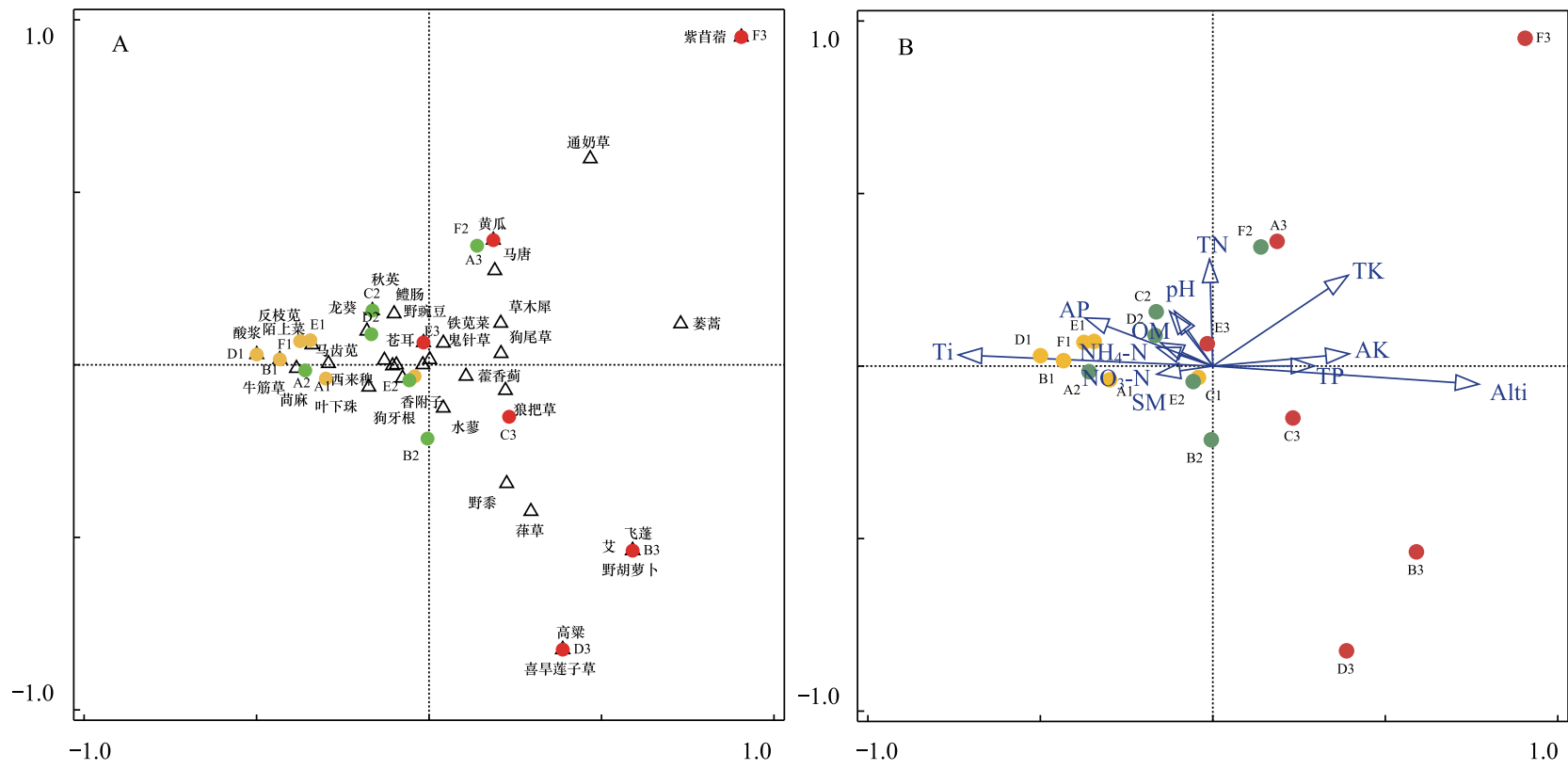

图 5 三峡水库䄰归段植物群落物种组成与采样点 CCA 排序图 (A) 和三峡水库䄰归段采样点与土壤因子 CCA 排序图 (B)

Fig.5 Plant species and sampling sites (A), Location of sampling sites and environmental variables (B), in the water level fluctuation zone of Three Gorges Reservoir defined by the first two axes in the canonical correspondence analysis

Alti : 海拔高度 Altitude; Ti : 水淹时间 Time; 圆圈代表不同的采样点 A1: 谭家湾 145-155 m; A2: 谭家湾 155-165 m;A3: 谭家湾 165-175 m;

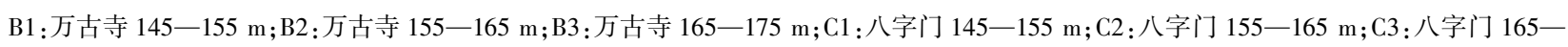
$175 \mathrm{~m}$; D1:海事处 145-155 m;D2:海事处 155-165 m; D3:海事处 165-175 m; E1: 龙潭河大桥 145-155 m; E2: 龙潭河大桥 155一165 m; $\mathrm{E} 3$ : 龙潭河大桥 165-175 m; F1: 杨家龙小学 145-155 m; F2 :杨家龙小学 155-165 m;F3:杨家龙小学 165-175 m

一年生草本植物大量生长发育是植物对环境变化不可预测的生态适应性结果, 三峡水库消落带干湿交替 的恶劣环境, 导致了一年生植物的生长优势。通过对蓄水前三峡库区消落带植被调查发现 ${ }^{[35]}$, 菊科和禾本科 分别占 $13.33 \%$ 和 $9.63 \%$; 三峡水库完全蓄水 $1 \mathrm{a}$ 后 ${ }^{[36]}$, 菊科和禾本科分别占 $14.06 \%$ 和 $17.19 \%$; 完全蓄水 $4 \mathrm{a}$ 后 (2014 年) ${ }^{[21]}$, 菊科和禾本科分别占 $6.68 \%$ 和 $13.73 \%$; 完全蓄水 $8 \mathrm{a}$ 后, 菊科和禾本科分别占 $26.47 \%$ 和 $20.59 \%$ 。科占比比较分析可见, 菊科和禾本科植物在三峡库区消落带植物中占优势地位, 菊科占比呈上升趋 势, 已经超越禾本科成为消落带第一大科。菊科占比沿低海拔到高海拔呈上升趋势, 也体现了菊科在各个海 拔的适应性与优势。菊科植物多为头状花序且花色多鲜艳, 易吸引昆虫为之授粉传播, 果实以瘦果为主, 种子 多密被冠毛等也方便自身借助风媒传播, 自身茎段可通过无氧呼吸进行营养繁殖, 同时耐干旱痊薄, 分布适应 性广的特点 ${ }^{[37]}$,均奠定了其在三峡水库消落带的优势种地位。

比较不同海拔梯度多样性指数发现, 物种数、Shannon 多样性指数及 Pielou 均匀度指数随海拔梯度的增 加而增加呈 “ 7 ”型变化, 这与三峡水库白夹溪消落带多样性指数的 “ $\wedge$ ” 型变化趋势不一致 ${ }^{[38]}$, 这可能与生 境异质性和特殊性有关。多样性指数在低海拔区域 (145-155 m) 与中海拔区域 (155-165 m) 间差异不明 显,而与高海拔区域 $(165-175 \mathrm{~m}$ ) 间差异显著。该结果与双向聚类分类结果相契合,低海拔与中海拔区域优 势物种较为相似。高海拔区域水淹胁迫较小, 物种定居较易, 同时高海拔植物群落受人为干扰因素的影响, 种 子飘落较多, 营养物质较丰富, 所以物种多样性较高。而在消落带中海拔区域, 属于半淹半露型消落带, 夏季 常面临高温干旱事件 ${ }^{[39]}$, 且陡坡较多 (平均 $\left.39^{\circ}\right)^{[22]}$, 因此水分有机物不易保留 ${ }^{[36,40]}$ 。恶劣的环境使得物种 多样性下降, 而部分耐水淹胁迫物种凭借其耐受水淹胁迫、耐受干旱及耐受贫癐的习性, 竞争力在此更为明 显, 因此先形成了以狗牙根为代表的单优群落。禾本科根系发达, 具有能够克隆繁殖的匍匐状地下根茎, 其侵 占性、再生性及抗恶劣环境能力极强 ${ }^{[41]}$, 这也对应了该区域禾本科植物与一年生植物占比较多的现象。低海 
拔区域受到较长时间和较高频率的水淹影响, 严酷的环境条件阻碍植物生长, 特别是高大木本植物的生长, 而 一年生的草本植物具有较强的环境适应性和较宽的生态幅, 成为消落带低海拔上的优势物种 ${ }^{[39]}$ 。同时,一年 生草本植物能够在退水后、蓄水前较短的时间内完成从种子到种子的生活史, 次年依靠临近种源或者土壤种 子库残留种子的萌发,而开始新的生命周期, 更容易在干扰剧烈的环境下生存 ${ }^{[42]}$ 。如图 $5 \mathrm{~A}$ 所示, 低海拔区域 高干扰的环境使部分竞争者 (如苍耳、鬼针草)不能发挥其优势,牛筋草、陌上菜这些萌发快、生活史短的一年 生物种得以在此存活 ${ }^{[43]} 。 2010$ 年 ${ }^{[36]}$ 植被调查中优势物种分别为荩草 $(0.922)$ 、狗牙根 $(0.561)$ 、狗尾草 $(0.428), 2014$ 年 ${ }^{[21]}$ 优势种为狗牙根 $(0.425)$ 、香附子 $(0.161)$ 、苍耳 $(0.071), 2016$ 年 $^{[15]}$ 优势物种为狗牙根 $(0.774)$ 、狗尾草 $(0.612)$ 、马唐 $(0.31)$, 本研究 2018 年优势种为狗牙根 $(0.444)$ 、鬼针草 $(0.357)$ 、苍耳 (0.242)。可见,随着蓄水周期的延长, 狗牙根在周期性水淹中确立了其优势地位。三峡库区高水位运行多年 后消落带狗牙根种群的地下茎物质储存与分配、营养芽形成与萌发、匍匐茎茎节与茎长伸长、分株形成与叶片 伸长、光合叶面积增量等均被显著促进,显著拓展了其作为单一物种的生境范围 ${ }^{[44]}$ 。另外, 荩草在刚水淹初 期是优势物种, 随着水淹周期的延长, 优势种地位正逐渐减弱, 群落分布面积逐渐减少, 说明该物种还没有形 成应对 $30 \mathrm{~m}$ 落差水位变动的完善响应机制。

通过对某种环境状况下生态系统在演替过程中土壤化学性质变化的研究, 可以更好的了解生态系统在演 变过程中地上与地下之间相互影响的联系与机制 ${ }^{[44]}$ 。本研究 CCA 分析表明, 海拔和水淹影响在植物群落空 间格局的形成中起着主导作用。河岸土壤性质的变化主要受水位波动影响,且 Ye 发现 $167.5 \mathrm{~m}$ 海拔以下受 到影响更为明显 ${ }^{[45]}$ 。海拔梯度的变化综合了水淹时间、水淹深度、温度、湿度和光照等多种环境因子, 因此, 在一定程度上能够显著地影响植物种群的空间分布格局。除水文机制外, 土壤营养因子决定着植物覆盖度和 生物量的大小, 同时影响着植物群落的组成、结构等特征 ${ }^{[46]}$ 。张志永等研究也表明, 高程和土壤有效氮是影 响三峡水库消落带植物重要值的主要生境因子 ${ }^{[47]}$ 。童笑笑等也发现土壤对植物群落分布的解释量最大, 水 文和地形次之, 历史土地利用类型最小 ${ }^{[16]}$ 。在本研究中, CCA 分析发现除水文因素外, 土壤 TN 和 TK 与物种 分布相关性较大, 表明 TN 和 TK 是决定消落带不同海拔高度植物群落物种分布和共存的主要因子。相关研 究表明植物群落较高的物种多样性与平衡的 $\mathrm{N} / \mathrm{P}(10-14)$ 密切相关 ${ }^{[48]}$ 。受氮元素限制的土壤增加氮元素 的供给植物的物种多样性会增加。而本研究中, 平均 N/P 比值为 $0.95 \pm 0.11$, 表明在三峡水库三峡水库剓归 段消落带土壤是受氮元素限制。岸生植被物种多样性在土壤达到 $K$ 最适宜的浓度 $(200 \mathrm{mg} \mathrm{K} / \mathrm{kg})$ 之前, 一般 有随着土壤 $\mathrm{AK}$ 浓度的增加物种多样性增加的趋势 ${ }^{[49]}$ 。在本研究中, 土壤 $\mathrm{AK}$ 浓度平均为 $(93.00 \pm 4.21) \mathrm{mg}$ $\mathrm{K} / \mathrm{kg}<200 \mathrm{mg} \mathrm{K} / \mathrm{kg}$, 表明消落带土壤同样也是受 K 元素限制。该结果印证了水淹后库区土壤元素含量下降 的研究 ${ }^{[1,50]}$, 消落带土壤养分状况目前仍处于较为贫瘦的状态, 是库区物种多样性下降的重要原因之一, 同 时 $\mathrm{N} 、 \mathrm{~K}$ 也成为了消落带植物生长、繁殖的限制因子。但根据双向聚类分析, 消落带以狗牙根群落、狗尾草 + 马 唐群落、鬼针草群落为优势种群, 这些植物一般对生境的适应性强、生态位宽, 能够更加有效的利用土壤养分, 对土壤养分含量要求低, 土壤养分含量对其生长、繁殖影响不大, 反而有利于狗牙根、狗尾草、马唐、鬼针草以 及苍耳等一年生和多年生的菊科和禾本科植物生长成为优势植物种群。童笑笑等 ${ }^{[16]}$ 对三峡水库澎溪河消落 带的植物群落进行分类得到狗牙根+雀稗群落、狗尾草+狗牙根群落、黄荆群落、白茅+鬼针草群落及苔草群落 等五个群落。而黄荆, 白茅等物种在此次库区剓归段消落带调查中未发现, 这可能是库区不同区域间的环境 异质性导致的。

在进行库区植被恢复与治理研究时,除探究植被水淹适应机制的同时，也应加强库区不同区域间的联系 交流和关注其差异性, 寻找其最合适具有本土特色的植被恢复方案。在本研究调查的 98 个样方群落中, 自然 恢复的 145-175 m 消落带植被中基本为草本植物群落。这一分布特征可能会在消落带演替初级阶段一直处 于主导地位。相关研究表明, 中山杉 (Taxodium 'Zhongshansha') ${ }^{[51]}$ 、中华蚊母树 (Distylium chinense) ${ }^{[52]}$ 及秋 华柳 (Salix variegata $)^{[53]}$ 等物种在库区具有较好的耐淹性, 能够改善土壤理化性质,有利于防止消落带水土流 失。因此, 在进行 (165-175 m) 高海拔消落带植被恢复时, 应增加上述耐受水淹的小乔木或灌木, 同时由于 
消落带为 $\mathrm{N}$ 和 $\mathrm{K}$ 元素限制土壤, 在人工进行群落构建植物配置时可以考虑播撒豆科植物, 增加土壤 $\mathrm{N}$ 的供 给, 同时增加 K 元素的施用, 并对水库消落带植被群落进行长期监测, 优化植被群落组成结构, 增加植物群落 的物种多样性,从而维持消落带生态系统稳定性。

\section{4 结论}

在经历 15 次水位涨落周年后,三峡水库䄰归段消落带植物多样性和植物群落结构发生较大改变,群落物 种多样性降低,不同海拔间差异性显著。水库消落带菊科与禾本科植物占优势地位,也包含高比例的单属单 种的科,物种多样性中低海拔异质性较小,与高海拔间差异较大。海拔和水淹影响是影响三峡水库䄰归段消 落带植物群落分布格局和多样性的主要因子,而消落带土壤受到 N、K 的限制。三峡库区消落带植物群落在 15 次水位涨落后,植物群落结构仍处于动态变化中。随着三峡水库持续调度运行,植物群落特征及土壤环境 因子仍会发生改变。因此,为了正确理解和预测大型水利水电工程建设运行对消落带植物群落特征变化的累 积效应及其生物多样性的维持机制,仍需要继续监测和研究消落带植物群落特征及其环境因子的时空变化。

\section{参考文献( References) :}

[ 1 ] Moura Júnior E G, Pott A, Severi W, Zickel C S. Response of aquatic macrophyte biomass to limnological changes under water level fluctuation in tropical reservoirs. Brazilian Journal of Biology, 2019, 79(1): 120-126.

[ 2 ] Stone R. China's environmental challenges. Three Gorges Dam: into the unknown. Science, 2008, 321(5889) : 628-632.

[ 3 ] 冯晶红, 刘瑛, 肖衡林, 刘暗, 吴耕华, 王可健. 三峡库区消落带典型植物光合固碳能力及影响因素. 水土保持研究, 2020, 27(1): 305-311.

[ 4 ] Gundersen P, Laurén A, Finér L, Ring E, Koivusalo H, Sætersdal M, Weslien J O, Sigurdsson B D, Högbom L, Laine J, Hansen K. Environmental services provided from riparian forests in the Nordic countries. AMBIO, 2010, 39(8) : 555-566.

[ 5 ] 刘维暐, 杨帆, 王杰, 王勇. 三峡水库干流和库湾消落区植被物种动态分布研究. 植物科学学报, 2011, 29(3): 296-306.

[ 6 ] Xu C, Xu Z H, Yang Z F. Reservoir operation optimization for balancing hydropower generation and biodiversity conservation in a downstream wetland. Journal of Cleaner Production, 2020, 245: 118885.

[ 7 ] Opheim T. Wetland losses continue but have slowed. National Wetlands Newsletter, 1997, 19(6) : 7-9.

[ 8 ] Nilsson C, Jansson R, Zinko U. Long-term responses of river-margin vegetation to water-level regulation. Science, 1997, 276(5313): 798-800.

[ 9 ] Nilsson C, Aradóttir Á L. Ecological and social aspects of ecological restoration: new challenges and opportunities for northern regions. Ecology and Society, 2013, 18(4): 35 .

[10] Nilsson C, Jansson R, Kuglerová L, Lind L, Ström L. Boreal riparian vegetation under climate change. Ecosystems, 2013, 16(3) : 401-410.

[11] Nilsson C, Polvi L E, Gardeström J, Hasselquist E M, Lind L, Sarneel J M. Riparian and in-stream restoration of boreal streams and rivers: success or failure? Ecohydrology, 2015, 8(5): 753-764.

[12] Benkwitt C E, Wilson S K, Graham N A J. Biodiversity increases ecosystem functions despite multiple stressors on coral reefs. Nature Ecology \& Evolution, 2020, 4(7): 919-926.

[13] Isbell F, Gonzalez A, Loreau M, Cowles J, Díaz S, Hector A, Mace G M, Wardle D A, O'Connor M I, Duffy J E, Turnbull L A, Thompson P L, Larigauderie A. Linking the influence and dependence of people on biodiversity across scales. Nature, 2017, 546(7656) : 65-72.

[14] 胡春宏, 方春明, 许全喜. 论三峡水库"蓄清排浑"运用方式及其优化. 水利学报, 2019, 50(1): 2-11.

[15] 郭燕, 杨邵, 沈雅飞, 肖文发, 程瑞梅. 三峡水库消落带现存植物自然分布特征与群落物种多样性研究. 生态学报, 2019, 39(12): 4255-4265.

[16] 童笑笑, 陈春娣, 吴胜军, 贾振毅, 易雪梅, 马茂华. 三峡库区澎溪河消落带植物群落分布格局及生境影响. 生态学报, 2018, 38(2) : 571-580.

[17］孙荣, 袁兴中, 丁佳佳. 三峡水库蓄水至 $156 \mathrm{~m}$ 水位后白夹溪消落带植物群落生态学研究. 湿地科学, 2010, 8(1): 1-7.

[18] Su X L, Bejarano M D, Yi X M, Lin F, Ayi Q, Zeng B. Unnatural flooding alters the functional diversity of riparian vegetation of the Three Gorges Reservoir. Freshwater Biology, 2020, 65(9): 1585-1595.

[19］贺秀斌, 鲍玉海. 三峡水库消落带土壤侵蚀与生态重建研究进展. 中国水土保持科学, 2019, 17(4): 160-168.

[20] Ye C, Butler OM, Chen C R, Liu W Z, Du M, Zhang Q F. Shifts in characteristics of the plant-soil system associated with flooding and revegetation in the riparian zone of Three Gorges Reservoir, China. Geoderma, 2020, $361: 114015$.

[21] 付娟, 李晓玲, 戴泽龙, 张海锋, 罗玉红, 胥㫪, 黄应平. 三峡库区香溪河消落带植物群落构成及物种多样性. 武汉大学学报: 理学版, 2015, 61(3): 285-290.

[22] Schönbrodt-Stitt S, Behrens T, Imbery S, Scholten T. Soil erosion modeling in terraced landscapes-examples from the Three-Gorges Area, China// Proceedings of the 19th World Congress of Soil Science, Soil Solutions for a Changing World. Brisbane, Australia, Published on DVD, 2010: 
228- 231 .

[23] 郭泉水, 康义, 洪明, 金江群, 朱妮妮, 聂必红, 王佐庆. 三峡库区消落带陆生植被对首次水陆生境变化的响应. 林业科学, 2013, 49 (5): $1-9$.

[24] Kabała C, Musztyfaga E, Gałka B, Łabuńska D, Mańczyńska P. Conversion of soil $\mathrm{pH}$ 1:2.5 $\mathrm{KCl}$ and 1:2.5 $\mathrm{H}_{2} \mathrm{O}$ to 1:5 $\mathrm{H}_{2} \mathrm{O}$ : conclusions for soil management, environmental monitoring, and international soil databases. Polish Journal of Environmental Studies, 2016, 25(2) : 647-653.

[25] Folch J, Lees M, Stanley G H S. A simple method for the isolation and purification of total lipides from animal tissues. Journal of Biological Chemistry, 1957, 226(1): 497-509.

[26] Beers Jr R F, Sizer I W. A spectrophotometric method for measuring the breakdown of hydrogen peroxide by catalase. Journal of Biological Chemistry, 1952, 195(1): 133-140.

[27] Williams V, Twine S. Flame photometric method for sodium, potassium and calcium//Peach K, Tracey M V, eds. Modern Methods of Plant Analysis. Berlin: Springer-Verlag, 1960: 3-5.

[28] Ye C, Cheng X L, Liu W Z, Zhang Q F. Revegetation impacts soil nitrogen dynamics in the water level fluctuation zone of the Three Gorges Reservoir, China. Science of the Total Environment, 2015, 517: 76-85.

[29] 席军强, 杨自辉, 郭树江, 王强强, 张剑挥, 王多泽. 人工梭梭林对沙地土壤理化性质和微生物的影响. 草业学报, 2015, 24(5): 44-52.

[30］盛茂银, 熊康宁, 崔高仰, 刘洋. 贵州喀斯特石漠化地区植物多样性与土壤理化性质. 生态学报, 2015, 35(2) : 434-448.

[31] 刘金虎. 秦岭西水河流域植物群落及其物种多样性的垂直格局研究 [D]. 杨凌: 西北农林科技大学, 2010.

[32] 方匡南, 陈远星, 张庆昭, 马双鸽. 双向聚类方法综述. 数理统计与管理, 2020, 39(1) : 22-34.

[33] 程瑞梅, 王晓荣, 肖文发, 郭泉水. 消落带研究进展. 林业科学, 2010, 46(4) : 111-119.

[34] Curtis J T, McIntosh R P. An upland forest continuum in the Prairie-forest border region of Wisconsin. Ecology, 1951, 32(3) : 476-496.

[35］江明喜, 党海山, 黄汉东, 陶勇, 金霞. 三峡库区香溪河流域河岸带种子植物区系研究. 长江流域资源与环境, 2004, 13(2): 178- 182.

[36] 王飞, 熊俊, 胥涛, 黄应平. 香溪河库岸植物群落及分布特点调查. 绿色科技, 2014, (1) : 88-91.

[37] Zhu K W, Chen Y C, Zhang S, Lei B, Yang Z M, Huang L. Vegetation of the water-level fluctuation zone in the Three Gorges Reservoir at the initial impoundment stage. Global Ecology and Conservation, 2020, 21: e00866.

[38］陈忠礼, 袁兴中, 刘红, 李波. 水位变动下三峡库区消落带植物群落特征. 长江流域资源与环境, 2012, 21(6)：672-677.

[39] 吴佳, 高学杰, 张冬峰, 石英, Giorgi F. 三峡水库气候效应及 2006 年夏季川渝高温干旱事件的区域气候模拟. 热带气象学报, 2011, 27 (1) : 44-52.

[40] Yao W M, Li C D, Zhan H B, Zhou J Q, Criss R E, Xiong S, Jiang X H. Multiscale study of physical and mechanical properties of sandstone in three gorges reservoir region subjected to cyclic wetting-drying of Yangtze River Water. Rock Mechanics and Rock Engineering, 2020, 53(5) : 2215-2231.

[41］冯洲博, 曹瑛, 许西梅, 杨宇超, 党军. 西安市麦田恶性禾本科杂草综合防控策略. 新疆农怎科技, 2017, 40(10): 28-29.

[42］罗文泊, 谢永宏, 宋凤斌. 洪水条件下湿地植物的生存策略. 生态学杂志, 2007, 26(9): 1478- 1485 .

[43] 申建红, 曾波, 类淑桐, 苏晓否, 黄文军. 三峡水库消落区 4 种一年生植物种子的水淹耐受性及水淹对其种子萌发的影响. 植物生态学 报, 2011, 35(3): 237-246.

[44] 李强, 丁武泉, 王书敏, 朱启红, 杨俊, 柯胜钱, 秦露, 杨林静, 郑捷月, 孟焱雯. 三峡库区多年高水位运行对消落带狗牙根生长恢复的 影响. 生态学报, 2020, 40(3): 985-992.

[45] Ye C, Chen C R, Butler O M, Rashti M R, Esfandbod M, Du M, Zhang Q F. Spatial and temporal dynamics of nutrients in riparian soils after nine years of operation of the Three Gorges Reservoir, China. Science of the Total Environment, 2019, 664: 841-850.

[46] Ye F, Ma M H, Wu S J, Jiang Y, Zhu G B, Zhang H, Wang Y. Soil properties and distribution in the riparian zone: the effects of fluctuations in water and anthropogenic disturbances. European Journal of Soil Science, 2019, 70(3): 664-673.

[47] 张志永, 程郁春, 程丽, 万成炎, 李金波. 三峡库区万州段消落带植被及土壤理化特征分析. 水生态学杂志, 2016, 37(2): 24-33.

[48] 张志永, 万成炎, 郑志伟, 邹䂀, 潘晓洁, 胡莲, 冯坤, 陈小娟. 三峡水库小江消落区生境异质性对植物群落影响. 长江流域资源与环境, 2013, 22(11): 1506-1513.

[49] Jansson R, Zinko U, Merritt D M, Nilsson C. Hydrochory increases riparian plant species richness: a comparison between a free-flowing and a regulated river. Journal of Ecology, 2005, 93(6): 1094- 1103.

[50］常超, 谢宗强, 熊高明, 储立民. 三峡水库蓄水对消落带土壤理化性质的影响. 自然资源学报, 2011, 26(7): 1236-1244.

[51] 殷云龙, 於朝广, 华建峰, 环姣姣, 韩路弯, 元白岩, 任凭, 吴晓洪, 祁小川. 重庆万州三峡库区消落带中山杉造林试验. 林业科技开发, 2014, 28(2): 110-114.

[52] Sun L, Li X L, Wang X S, Xiang L, Yang J, Min Q F, Chen G H, Chen F Q, Huang C M, Wang G X. Growth and respiratory metabolic adaptation strategies of riparian plant Distylium chinense to submergence by the field study and controlled experiments. Plant Physiology and Biochemistry, 2020, 157: 1-12.

[53] 李娅, 曾波, 叶小齐, 乔普, 王海锋, 罗芳丽. 水淹对三峡库区岸生植物秋华柳 ( Salix variegata Franch.) 存活和恢复生长的影响. 生态学 报, 2008, 28(5): 1923-1930. 